\title{
An Approach towards Analysis of Microblogging with Twitter for Evaluating the Branding Trends
}

\author{
Anil Ahir ${ }^{1}$, Santosh Tamboli ${ }^{2}$ \\ ${ }^{1}$ Mumbai University, Vidyalankar Institute of Technology, Mumbai, India \\ ${ }^{2}$ Assistant Professor, Vidyalankar Institute of Technology, Mumbai, India
}

\begin{abstract}
In this project we report study results investigating tweets from various tweeter account holder as a micro-blogging their thoughts and ideas as a form of electronic word-of-mouth for distributing consumer sentiments concerning products. We investigated some micro-blog postings containing labeling comments, sentiments, and opinions. We examined the overall structure of these tweets the types of expressions, and the movement in positive or negative sentiment. We equated automated methods of classifying sentiment in these tweets with manual coding. By this approach we analyzed the range, frequency, timing, and content of tweets In examining tweets for structure and arrangement, the linguistic structure of tweets approximate the linguistic patterns of natural language expressions. We find that twitter is an online tool for customer word of mouth communications and discuss the implications for corporations using micro-blogging as part of their overall marketing strategy.
\end{abstract}

Keywords: Branding, Tweets, polarity, Microblogging

\section{Introduction}

Detecting and identifying the sentiments of the user/s of a particular brand or an event is becoming an important factor to consider when taking care of a large and a varied audience. A sentiment can be defined as an "Expression". These sentiments define a brand or a products success within its users/ consumers. Thus, a timely sentiment checking can not only help the brand to address the needs of the consumers correctly but also save the brand. A timely step can save the brand.

Identifying the pain area of a consumer is critical for the timely acknowledgement of events, like failures in service or defamation etc. that can affect the brands performance and image. An event can be said in both positive and negative statement. The event on any micro-blogging website can range from an appreciation for the quality or satisfaction from the consumable product, or it can be a negative remark like delay in delivery or irresponsible behavior towards a customer by a brand. While studying the remarks made, affecting a brands image, we consider actions/mentions in both the form positive and negative. This technique is the last line of defense when other approaches fail. The foremost challenge in identifying and detecting a positive or a negative remark is the fact that they can be caused by a vast set of events. While studying, researchers have pose number of interesting research problems like modeling, involving statistics and efficient data structure. Nevertheless researchers have not yet gain widespread adaption, as a number of challenges, like calibration and reducing number of false positive rate remain to be unsolved.[1]

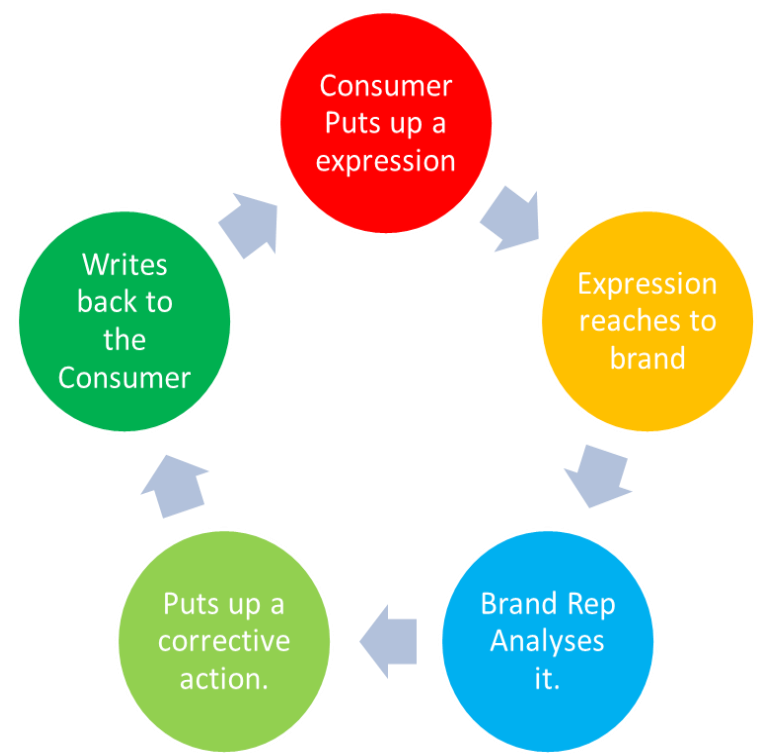

Figure 1: Cycle of Sentiment Analysis.

Motivated by this, the problem of identifying the sentiments of the consumers correlated with a brand or product during a time interval. Sentiments of an entity reflects the goal of gaining the more information about the consumers perception which or without additional meta-data, is often meaningless for the analysis. Data mining techniques are used to identify anomalous behavior. Identified sentiments of a brand or a product by a consumer can be used for a number of applications, like implementing market strategy, user perception, brand loyalty or any event causing an outrage.

\section{Problem Definition}

To identify an event during a time interval and address the events need to the consumer of the respective brand. The system contains three different phases. One is collecting the data set that will of the brands. Second phase consists of analyzing the tweets. Finally third phase is to apply score to find the prevailing sentiments.

Volume 5 Issue 6, June 2016 www.ijsr.net 


\section{International Journal of Science and Research (IJSR) \\ ISSN (Online): 2319-7064}

Index Copernicus Value (2013): 6.14 | Impact Factor (2015): 6.391

\section{Scope}

\section{In Scope}

1] Fetching Tweets from the Social Network

2] Sentiment Analyzer will observe the sentiments for certain interval.

3] Basis the sentiments of the tweets collected the score shall be given to the word.

\section{Out Scope:}

1] A number of possible directions for future research exist. Optimizing the sentiment analyzer for a higher scalability and efficiency of frequent brand-set.

\section{Proposed System}

A number of studies have focused on developing sentiment analysis detection system. In provides a good characterization of different types of sentiments expressed by the users of the particular brand on Twitter. I have tried to introduce a general framework that aims to simplify the sentiments expressed on Twitter. They are successful in identifying sentiments that are generated by the users.

Keyword/pattern-based techniques are different from other techniques with respect to the measurement metric. The metrics used in a keyword/pattern-based technique is extracted from the tweet, and commonly includes phrases, abbreviations, smileys or as they are called emoticons/ emojis.

Thus the total extraction of the information from the data is more accurate this gives the user a better vantage to make a call by seeing the information and its flow.

This vantage for the user is the key towards survival in the social media world as the word about a brand and its image spreads like wild fire and can wreak havoc or create a considerable damage which is irreversible to the brand entity.

\subsection{The Algorithm}

The algorithm proposed for this particular project has been kept simple.The algorithm executes under two parts.

1. Identification

2. Classification.
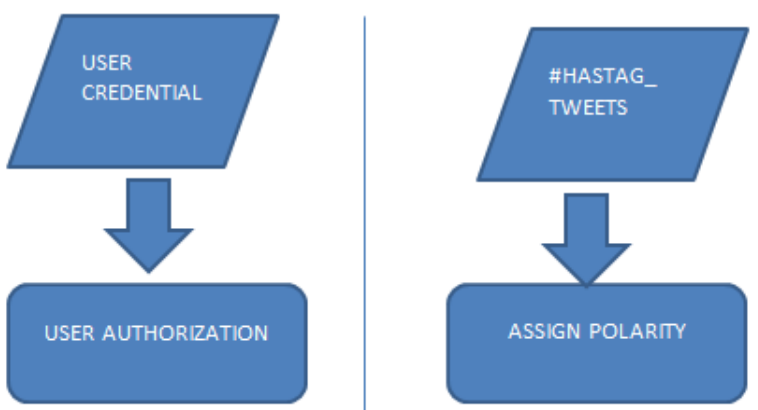

The execution of the system can be shown in the following pseudo manner.
A. The system starts pulling out tweets from twitter with the help of an API.

B. The tweets are pulled basis a Hashtag which is currently trending.

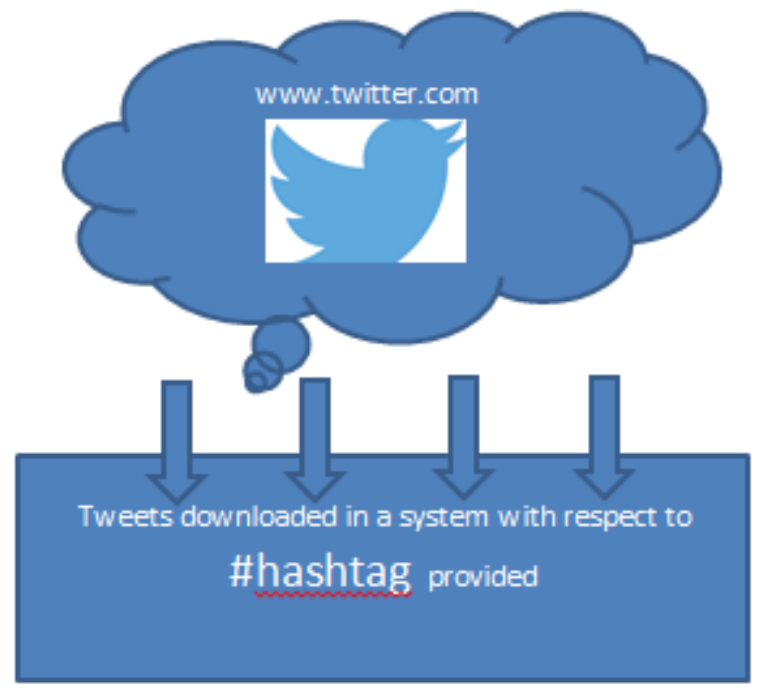

C. The Hashtagged tweet is then pushed onto the staging database.

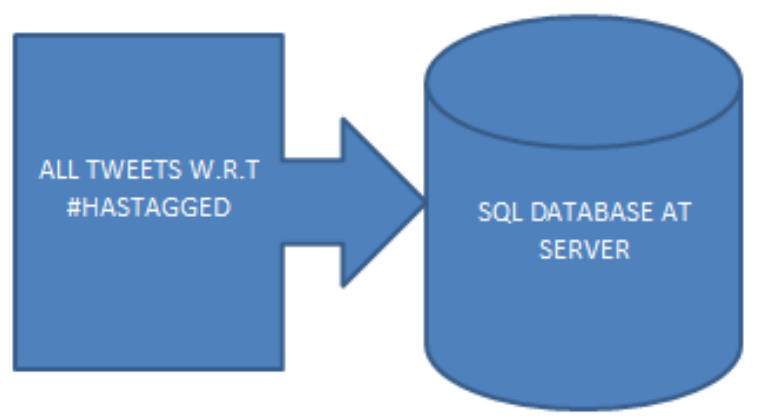

D. The collection of hashtag is then assorted basis the polarity.

E. The polarity is then assigned to tweet.

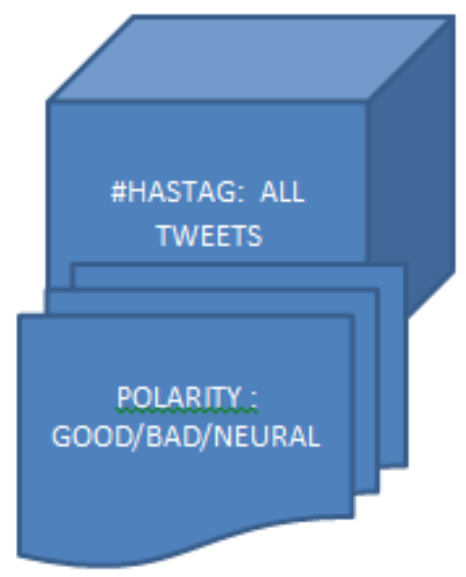

\section{F. The data is written back to the database.}

\section{a) Identification}

Identification of the expression is the most important steps in the entire algorithm and hence this section is completely dedicated to it. The tweets are pulled via an API then the 


\section{International Journal of Science and Research (IJSR) \\ ISSN (Online): 2319-7064 \\ Index Copernicus Value (2013): 6.14 | Impact Factor (2015): 6.391}

tweets are pushed in a staging area. From the staging area the programme assorts the tweets. In this the tweets that are relevant are identified and pushed in for the next stage of the algorithm.

\section{b) Classification}

This is the second important stage of the algorithm the classification. The classification of a tweets basically means to extract a sentiment from the tweet and assign a polarity to it. This further enhances the algorithms processing capacity as a Boolean value is associated with the tweet. Thus classification is an important step. The classification also plays a major role in deducing the tweets sentiment when it comes to emojis or use of internet abbreviation expression. The abbreviation expressions are a part of substantial number of tweets and hence needs to be addressed. [4]

\section{Discussion and Analysis}

There are numerous suggestions of our study. Tweets can be used to provide evidence or draw feedbacks to criticize the brands. As such, checking and leveraging social posting sites concerning one's own brand and the brand of competitors provides valuable competitive intelligent information. Companies can receive polarity feedback or brand exposure via reviewers and others who micro-blog about the company and products.

With the proposed tools, companies can track micro-blog postings and immediately get involved with unhappy customers. Companies can get near real-time feedback, by setting up corporate accounts, from customers using microblog polls, and surveys. Organizations can get valuable contents and product improvement ideas by tracking microblog postings and following those people who follow their corporate accounts. Companies can leverage contacts made via micro-blogging service to further their branding efforts by responding to comments about the company brand. [2]

\section{Conclusion}

With the evolvement of twitter it becomes helpful to be in touch with the latest trends on brands. It is a kind of review where every new user likes to know before buying or know particular brand or product. It is obvious that micro-blogging services such as Twitter could become key applications in the attention economy. Given the ease of monitoring any brand' sentiment, one can view micro-blogging as a promising competitive intelligence source.

\section{References}

[1] Mr. Sandeep J. Kamble, Prof.Sachin Deshpande, "Survey on Anomaly Extraction System Using Featured Histogram and Mining Rules," International Journal of Scientific \& Engineering Research, Volume 6, Issue 3, March-2015 384 ISSN 2229-5518

[2] Bernard J. Jansen, Mimi Zhang “ Micro-blogging as Online Word of Mouth Branding” CHI 2009 Spotlight on Works in Progress April 4-9, 2009 Boston, MA, USA.
[3] Ethel Lee "Impacts Of Social Media On Consumer Behavior. Decision Making Process." BACHELOR'S THESIS ABSTRACT TURKU UNIVERSITY OF APPLIED SCIENCES International Business | Bachelor of Business Administration May 2013

[4] Apoorv Agarwall J Asnee T Singh Sabharwal" End-ToEnd Sentiment Analysis of Twitter Data" proceedings of the Workshop on Information Extraction and Entity Analytics on Social Media Data, Pages 39-44, Coling 2012, Mumbai, December 2012 